DOI 10.2478/auseb-2021-0004

\title{
Price Markups and Upstreamness in World Input-Output Data
}

\section{Constantin COLONESCU}

MacEwan University, Department of Economics

colonescuc@macewan.ca

\begin{abstract}
This research uses the publicly available World Input-Output Database (WIOD) to investigate the relationship between an industry's markup and its upstreamness, the industry's position in the vertical chain of production; the research also identifies common attributes among highmarkup industrial sectors: higher-markup industries display a higher level of capital compensation and a lower share of labour and other inputs in the value of output. Finally, it is found that upstream industries, those producing mostly raw materials and intermediate products enjoy higher market power than their downstream counterparts. This result could be among the first in the literature to find evidence of double marginalization at an industry level of aggregation. It also suggests that virtually all final product prices may incorporate substantial markups through their inputs.
\end{abstract}

Keywords: world input-output table, price markup, upstreamness

JEL classification: D24, D42, L11, L12, L41, L42

\section{Introduction}

While mainstream economics has firmly embraced theories of rent seeking and market power, many economists and policy makers are still convinced that markets are mostly competitive and efficient. This erroneous belief has consequences on some of the most pressing of today's global problems such as economic inequality (Han and Pyun, 2020; Thomas, 1980; Ennis, Gonzaga, and Pike, 2019), indebtedness, and financial crises (Montero and Urtasun (2021) address to some extent the connection between markup and financial pressure in times of crisis).

Economists and policymakers make better decisions concerning pressing global problems when they have access to accurate measures of market power and become aware of its prevalence. This paper consolidates previous contributions to measuring market power, suggesting that market power is the norm rather than the exception in world economies. To that end, it uses the World Input-Output Database (WIOD, 
the 2017 and 2012 releases) provided by the European Commission (Timmer et al., 2015). As for the method, it uses a production approach model pioneered by a series of papers (Robert E. Hall, Blanchard, and Hubbard, 1986; Robert E. Hall, 1988) and subsequently developed by others (De Loecker, 2011; De Loecker and Warzynski, 2012; De Loecker et al., 2016; De Loecker and Eeckhout, 2017; Robert E. Hall, 2018); it also uses an upstreamness model proposed by Antràs et al. (2012b).

Many markets depart to various degrees from the perfectly competitive model, a departure that can be measured by the ratio between price and marginal cost (markup). This paper finds a median markup of 1.36 with an average of 1.5, consistent with other measurements (De Loecker and Eeckhout, 2018; De Loecker, Eeckhout, and Unger, 2020) but higher than other estimates (Montero and Urtasun, 2021 - Table 5). Differences in estimates are to be expected given the diversity of regions, industries, periods, and aggregation levels that are used in different studies.

Why would market power be the norm rather than the exception in the economies of the world? I dub a complex market structure a market where a final product incorporates intermediate (upstream) products that come from both vertical and horizontal markets with various degrees of monopolization (Machlup and Taber, 1960). In a successive, or vertical monopoly model, an upstream monopoly sells an intermediate product to a downstream company, which is itself a monopoly selling an intermediate product to its further downstream counterpart, and so on. In a vertical chain like this, each transaction happens at a price reflecting a company's market power, a process known as double marginalization (Spengler, 1950; Bresnahan and Reiss, 1985) but which should indeed be named multiple marginalization. In another possible arrangement, parallel monopolies (or side-byside monopolies in the language of Machlup and Taber (1960)) sell intermediate, complementary inputs separately to a final-product manufacturer or to another intermediate-product one.

Virtually, every final good or service incorporates substantial upstream monopoly markups because every final good and service is the product of interdependent, complex markets. Here is an example: The production of wheat, which is many economics teachers' preferred example of a highly competitive market, uses inputs produced in quasi-monopolistic sectors such as steel, agricultural machinery, chemicals, pesticides, and others. To my knowledge, a theoretical model of a complex market structure as described here is yet to be developed.

World input-output tables are used here to calculate aggregate markups at sector and country levels; while several authors estimate price markups to assess macroeconomic effects, here the interest is mostly to identify the common attributes of high-markup sectors and to explore the relationship between a sector's position in a vertical production chain (its upstreamness index) and its market power. (The words sector and industry are used interchangeably.) 
This paper establishes a positive relationship between price markup measured by the price to marginal cost ratio and an upstreamness index in the vein of Antràs et al. (2012b), with its more extended version - Antràs et al. (2012a). Besides developing a method of calculating upstreamness (defined as an industry's distance from final product) based on input-output tables, Antràs et al. (2012b) calculate upstreamness indices for a set of countries and seek common features among high-upstreamness countries.

The remaining of the paper is structured as follows. Section 2 provides a simplified version of the theory behind production-based markup calculations. Section 3 identifies the data source and calculates descriptive statistics. Section 4 calculates markups and upstreamness indices for each sector-country-year observation and shows their averages at country and sector levels. Section 5 develops a linear regression model seeking relationships between markup and various sector attributes. Finally, Section 6 contains conclusions and suggests directions for further research.

\section{The Production Approach to Markup: Theory and Method}

Here is a simplified version of the markup model envisioned by Robert E. Hall (1988) and his followers, in particular De Loecker and Warzynski (2012), of which a simpler version is available in De Loecker, Eeckhout, and Unger (2020). The method has been dubbed the production approach to markup calculation in De Loecker and Warzynski (2012) and can be described as follows. Given a target level of production, $Y_{0}$, a producer minimizes costs in the short run by choosing the amount of a generic intermediate input, $L$; this generic input can be any variable input such as an intermediate product or labour. A variable input is one whose quantity can be changed at any time without an adjustment cost. In this context, capital is not adjustable and counts as a fixed input, which cannot be adjusted for minimizing costs. Equation (1), where $Y(L)$ represents the production function, describes the cost minimization problem, with its first-order condition given by Equation (2).

$$
\begin{gathered}
\operatorname{Min}\{w L+r K\} \text { such that } Y(L)=Y_{0} \\
w=\lambda \frac{\partial Y}{\partial L}
\end{gathered}
$$


By the envelope theorem, the Lagrangean multiplier in the cost minimization problem, $\lambda$, is equal to the change in the cost function, which is our objective function at its minimum level, when the target quantity of output increases by one small unit; this makes $\lambda$ the marginal cost of production. Let us multiply Equation (2) by $L / P Y$, where $P$ is the price of output, and slightly re-arrange the resulting equation:

$$
\frac{w L}{P Y}=\frac{\lambda}{P} \frac{\partial Y}{\partial L} \frac{L}{Y}
$$

Equation (3) can be easier to interpret using the following notations, where $\theta_{L}$ is the elasticity of output with respect to the variable input, $\alpha_{L}$ is the share of the cost of the variable input in the revenue from selling the quantity of output $Y$ at price $P$, and $\mu$ is the markup ratio, price over marginal cost:

$$
\theta_{L}=\frac{\partial Y}{\partial L} \frac{L}{Y} ; \quad \alpha_{L}=\frac{w L}{P Y} ; \quad \mu=\frac{P}{\lambda}
$$

As the subscript $L$ indicates in Equation (4), the input elasticity, $\theta_{L}$, and the input cost share in revenue, $\alpha_{L}$, are specific to each variable input, while the markup ratio, $\mu$, is the same for all inputs. This observation allows us to use any variable input for which we can find data to estimate the markup. With these notations, we can re-write Equation (3) as follows:

$$
\mu=\frac{\theta_{L}}{\alpha_{L}}
$$

Equation (5) gives a remarkably compact expression for the markup of each company (or sector) and for each period; the difficulty is to estimate the share of input expenditure in total revenue and the elasticity as data on input and output prices and quantities are often not available. As De Loecker and Warzynski (2012, 2444) show, an input elasticity can be estimated by modelling a production function under certain restrictions.

Industry input elasticities, $\theta$, are calculated here by estimating a constant elasticity production function using the $\mathrm{R}$ package prodest (Rovigatti 2017a). The estimation is based on a method proposed by Olley and Pakes (1996), with subsequent amendments by Levinsohn and Petrin (2003) and Ackerberg, Caves, and Frazer (2015). This method uses a consistent, two-step estimation of the production function shown in Equation (6), as given in Rovigatti (2017a, 2).

$$
y_{i t}=\beta_{0}+l_{i t} \beta_{l}+k_{i t} \beta_{k}+\omega_{i t}+\epsilon_{i t}
$$


In Equation (6), $y$ is a measure of output, $l$ is labour (the free variable in the language of Rovigatti (2017a)), and $k$ is capital (the state variable). Subscript $i$ identifies one country-sector entry, and $t$ is the time variable.

\section{Data}

The data used in these calculations come from the World Input-Output Database, Socio-Economic Accounts (WIOD-SEA), funded by the European Commission and freely available at WIOD-SEA (2018). The database collects yearly data for the period 1995 through 2009 for 40 countries and 35 industrial sectors. Erumban et al. (2012) give a detailed description of the primary data sources and the methods that have been used to compile the WIOD-SEA dataset.

Table 1 shows descriptive statistics of the data, including four calculated variables in its last rows. The variables year, country, and industry code are not shown in the table, but the lists of sectors and countries are available in figures 1 and 2 . Although the dataset has a panel data structure, the regression model treats it as a pooled dataset, assuming production function parameters remain stable for longer periods.

As a side note, an interesting fact revealed in Table 1 is that the overall average of the Capital Compensation variable is a large share (67\%) of Compensation of Employees. In other words, a relatively small number of capital owners receive a relatively large share of income.

Table 1. Descriptive statistics

\begin{tabular}{llcc}
\hline Code & Var. Name & Mean & Max \\
CAP & Capital Compensation (mil) & $3.3 \mathrm{E}+05$ & $6.4 \mathrm{E}+07$ \\
COMP & Compensation of Employees (mil) & $4.9 \mathrm{E}+05$ & $5.5 \mathrm{E}+07$ \\
EMP & No. of Persons Engaged (1000) & $1.5 \mathrm{E}+03$ & $3.6 \mathrm{E}+05$ \\
EMPE & No. of Employees (1000) & $6.4 \mathrm{E}+02$ & $1.0 \mathrm{E}+05$ \\
GFCF & Gross Fixed Capital Formation & $3.1 \mathrm{E}+05$ & $5.4 \mathrm{E}+07$ \\
GFCF_P & Price Level GFCF & $3.1 \mathrm{E}+02$ & $4.7 \mathrm{E}+03$ \\
GO & Gross Output (mil) & $2.2 \mathrm{E}+06$ & $2.8 \mathrm{E}+08$ \\
GO_P & Price Level Gross Output & $3.4 \mathrm{E}+02$ & $5.0 \mathrm{E}+04$ \\
GO_QI & Gross Output, Volume Indices & $1.5 \mathrm{E}+02$ & $4.7 \mathrm{E}+03$ \\
H_EMP & Hours Worked by Persons Engaged (mil) & $3.0 \mathrm{E}+03$ & $6.1 \mathrm{E}+05$ \\
H_EMPE & Total Hours Worked by Employees (mil) & $1.2 \mathrm{E}+03$ & $2.3 \mathrm{E}+05$ \\
H_HS & Hours Worked by High-Skilled Persons (share) & $1.9 \mathrm{E}-01$ & $9.2 \mathrm{E}-01$ \\
H_LS & Hours Worked by Low-Skilled Persons (share) & $3.2 \mathrm{E}-01$ & $9.8 \mathrm{E}-01$
\end{tabular}




\begin{tabular}{llll} 
H_MS & Hours Worked by Medium-Skilled Persons (share) & $4.9 \mathrm{E}-01$ & $9.3 \mathrm{E}-01$ \\
II & Intermediate Inputs, Value (mil) & $1.2 \mathrm{E}+06$ & $2.1 \mathrm{E}+08$ \\
II_P & Intermediate Inputs, Price & $3.3 \mathrm{E}+02$ & $5.0 \mathrm{E}+04$ \\
II_QI & Intermediate Inputs, Volume Indices & $1.6 \mathrm{E}+02$ & $5.5 \mathrm{E}+03$ \\
K_GFCF & Real Fixed Capital Stock & $3.5 \mathrm{E}+06$ & $1.1 \mathrm{E}+09$ \\
LAB & Labour Compensation (mil) & $6.5 \mathrm{E}+05$ & $7.8 \mathrm{E}+07$ \\
LABHS & High-Skilled Labour Compensation (share) & $2.7 \mathrm{E}-01$ & $9.7 \mathrm{E}-01$ \\
LABLS & Low-Skilled Labour Compensation (share) & $2.7 \mathrm{E}-01$ & $9.8 \mathrm{E}-01$ \\
LABMS & Medium-Skilled Labour Compensation (share) & $4.7 \mathrm{E}-01$ & $9.1 \mathrm{E}-01$ \\
VA & Gross Value Added (mil) & $9.9 \mathrm{E}+05$ & $7.3 \mathrm{E}+07$ \\
VA_P & Gross Value Added, Price Levels & $3.6 \mathrm{E}+02$ & $5.0 \mathrm{E}+04$ \\
VA_QI & Gross Value Added, Volume Indices & $1.4 \mathrm{E}+02$ & $1.2 \mathrm{E}+04$ \\
theta & Intermediate-Input Elasticity & $7.6 \mathrm{E}-01$ & $9.8 \mathrm{E}-01$ \\
alpha & Intermediate-Input Share in Output & $5.5 \mathrm{E}-01$ & $1.0 \mathrm{E}+00$ \\
mu & Markup (Price to Marginal Cost Ratio) & $1.5 \mathrm{E}+00$ & $1.4 \mathrm{E}+01$ \\
upstrIndex & Upstreamness (More Upstream = Higher Index) & $2.1 \mathrm{E}+00$ & $2.2 \mathrm{E}+01$ \\
\hline
\end{tabular}

\section{Markup and Upstreamness Calculations}

The purpose of this section is to determine price markup and upstreamness indices for each sector-country-year observation and to visualize these results at country and sector levels. To do so, we first calculate input elasticities, $\theta$, and input expenditure shares, $\alpha$; then we use these two variables in Equation (5) to calculate the markups. Identifying the determinants of sector-level markups in a regression model is reserved for the next section.

\subsection{Input Elasticities and Input Shares}

To determine input elasticities, Equation (6) is estimated using the following variables: GO_QI (volume indices of gross output, the dependent variable), II_ QI (intermediate inputs, volume indices), K_GFCF (real fixed capital stock), and GFCF/GFCF_P (nominal capital formation divided by the relevant price index). Gross fixed capital formation has been collected from the Socio-Economic Account part of WIOD 2012. The calculations are performed using the prodest package (Rovigatti 2017b), namely its prodestOP function.

The result of this calculation is the technological parameter $\theta$, which is the same for all countries and years but specific to each sector. Separately, I calculate the 
share of intermediate inputs in total revenue, $\alpha$, directly from the socio-economic accounts part of the WIOD table, as the ratio II/GO; since $\alpha$ is different for each sectorcountry-year observation, the markup, $\mu$, will also be different for each observation.

\subsection{Markup by Sector}

Figure 1 displays markups and their 95\% confidence intervals by industry, averaged over countries; industry categories correspond to the ISIC Rev. 3 standard. The graph shows that real estate, financial intermediation, and retail trade make the top of the list with the highest markups, with public administration, some energy sectors, and food industries showing the lowest markups. One should keep in mind, though, that this picture could be very different at a lower level of aggregation.

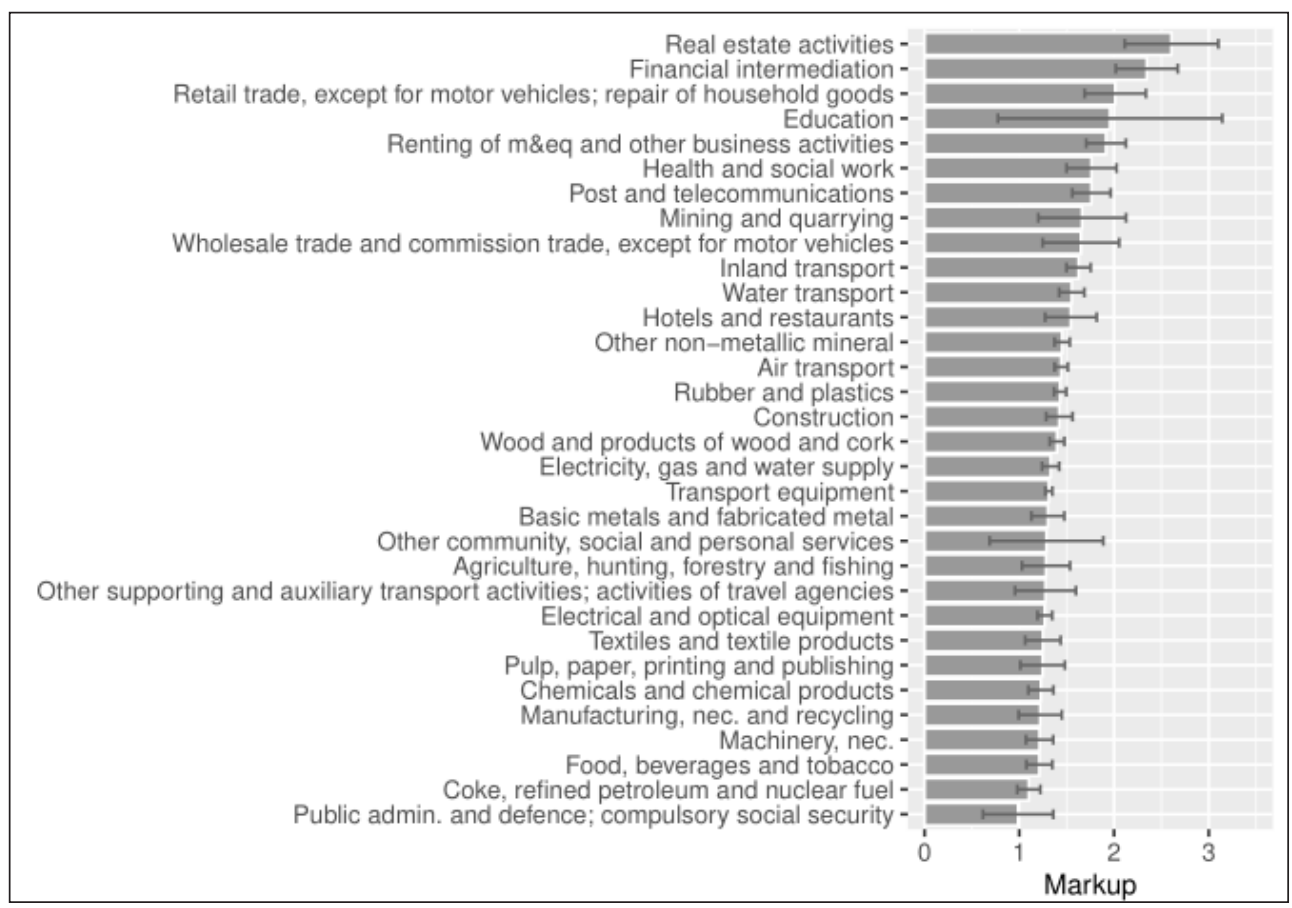

Figure 1. Average markup by sector

\subsection{Markup by Country}

Figure 2 shows markups with their 95\% confidence intervals by country from highest to lowest. The countries with the highest aggregate markup are India, Mexico, Greece, Cyprus, and Brazil, while Estonia and the Czech Republic have 
the lowest markups. Such a comparison, though, may not be very relevant because of the high level of aggregation across sectors: A balanced, diversified economy may have a lower aggregate markup than a non-diversified one, although variance across sectors may be higher.

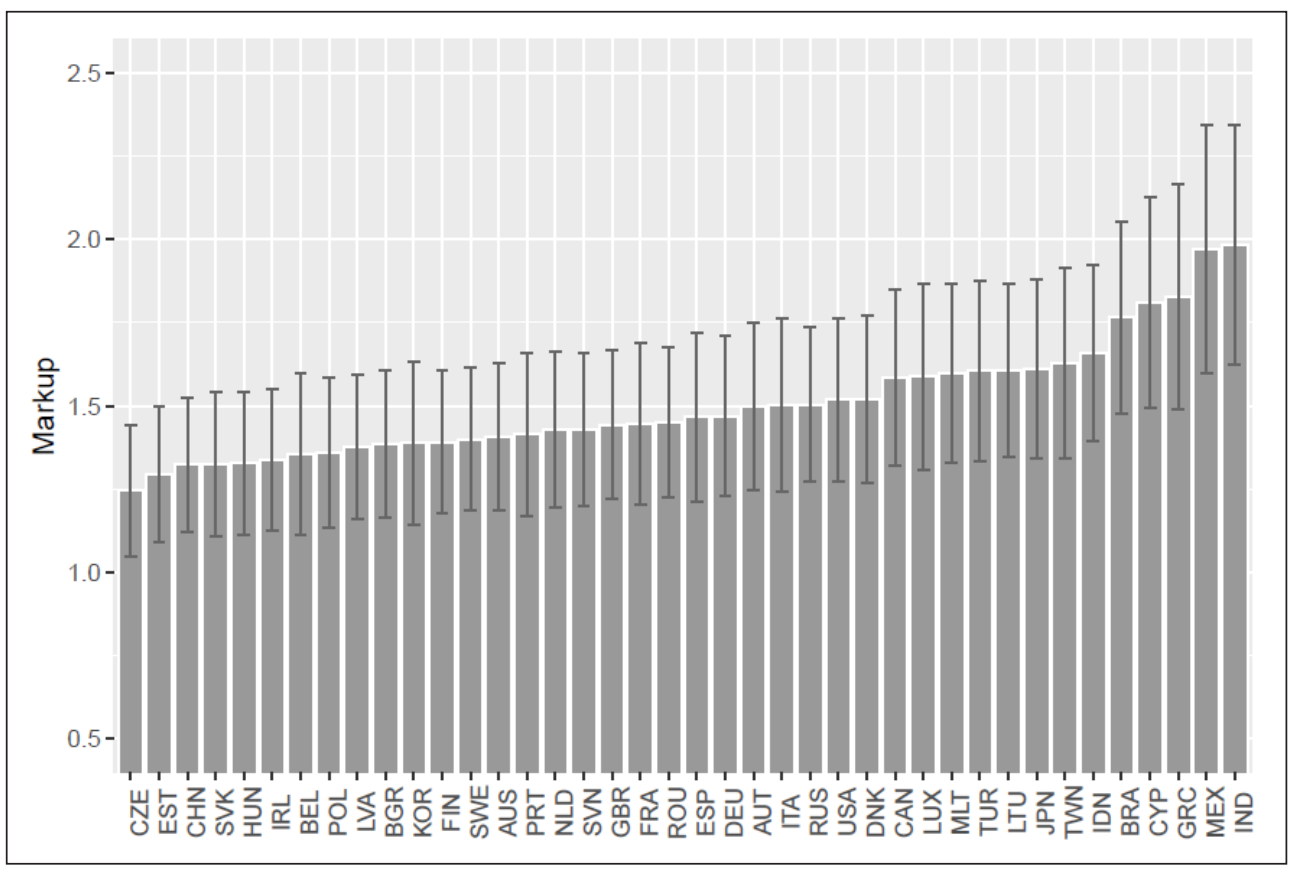

Figure 2. Average markup by country

\subsection{Calculating the Upstreamness Index}

The upstreamness index is calculated using the complete input-output tables, not only the Socio-Economic Accounts part, of World IO Tables (2018), which are also provided by the European Commission and are freely available. Upstreamness can be calculated based on a method developed by Antràs et al. (2012b), using the $\mathrm{R}$ package ioanalysis (Wade and Sarmiento-Barbieri, 2019). Equation (7) follows Joolman (2020: 14).

$$
d_{i j}=a_{i j} \frac{x_{i}}{x_{i}+e_{i j}-m_{i j}} ; \quad U=(I-D)^{-1} ; \quad u_{i}=\Sigma_{\mathrm{j}=1}^{\mathrm{n}} U_{i j}
$$


In the language of Joolman (2020), the notations in Equation (7) have the following meanings: $a_{i j}$ represents the share of input $i$ in industry $j, x_{i}$ represents the total output generated by sector $i, e_{i j}$ stands for exports, $m_{i j}$ for imports, and $D$ is the matrix having $d_{i j}$ for its elements; $u_{i}$ represents industry $i$ 's upstreamness index, which is "weakly" bounded downward by 1 (Wade and Sarmiento-Barbieri, 2019).

Higher values of the upstreamness index indicate a more "upstream" sector, one that provides a higher share of its output as input to other, downstream industries. Intuitively, the upstreamness index associated with sector $i$ can be thought of as "the dollar amount by which output of all sectors increases following a one-dollar increase in value added in sector $i$ ” (Antràs et al., 2012b: 413). Figure 3 shows the calculated upstreamness indices by sector. The results are consistent with those in other sources such as Antràs et al. (2012b: 415).

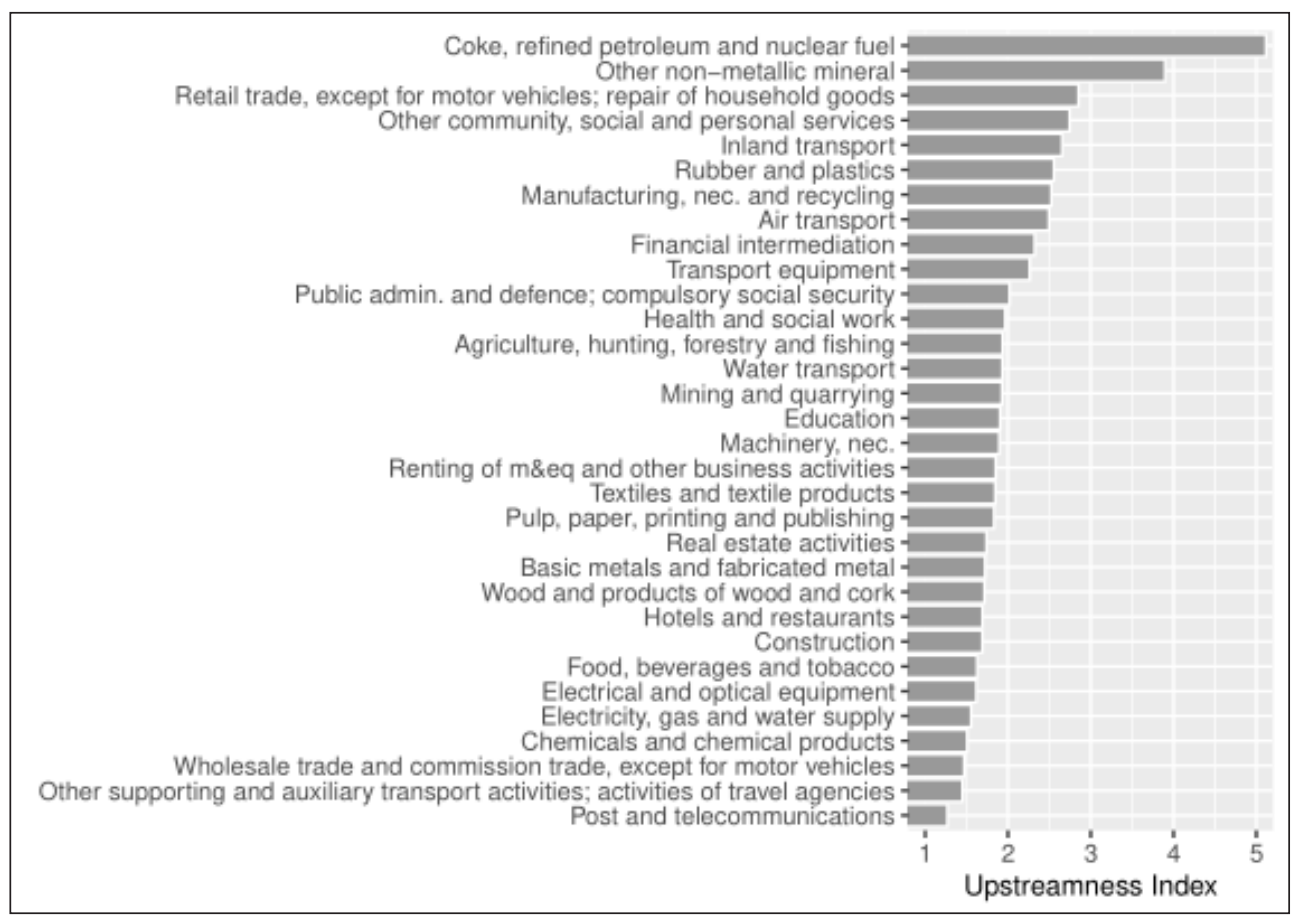

Figure 3. Average upstreamness by sector

Figure 4 shows upstreamness levels by country, although country averages may be less informative at this level of aggregation. The graph shows Spain at the highest level, followed at a distance by Japan and Australia. The lower end belongs to three Central-East European countries, Poland, the Czech Republic, and Slovenia, three relatively small economies. 


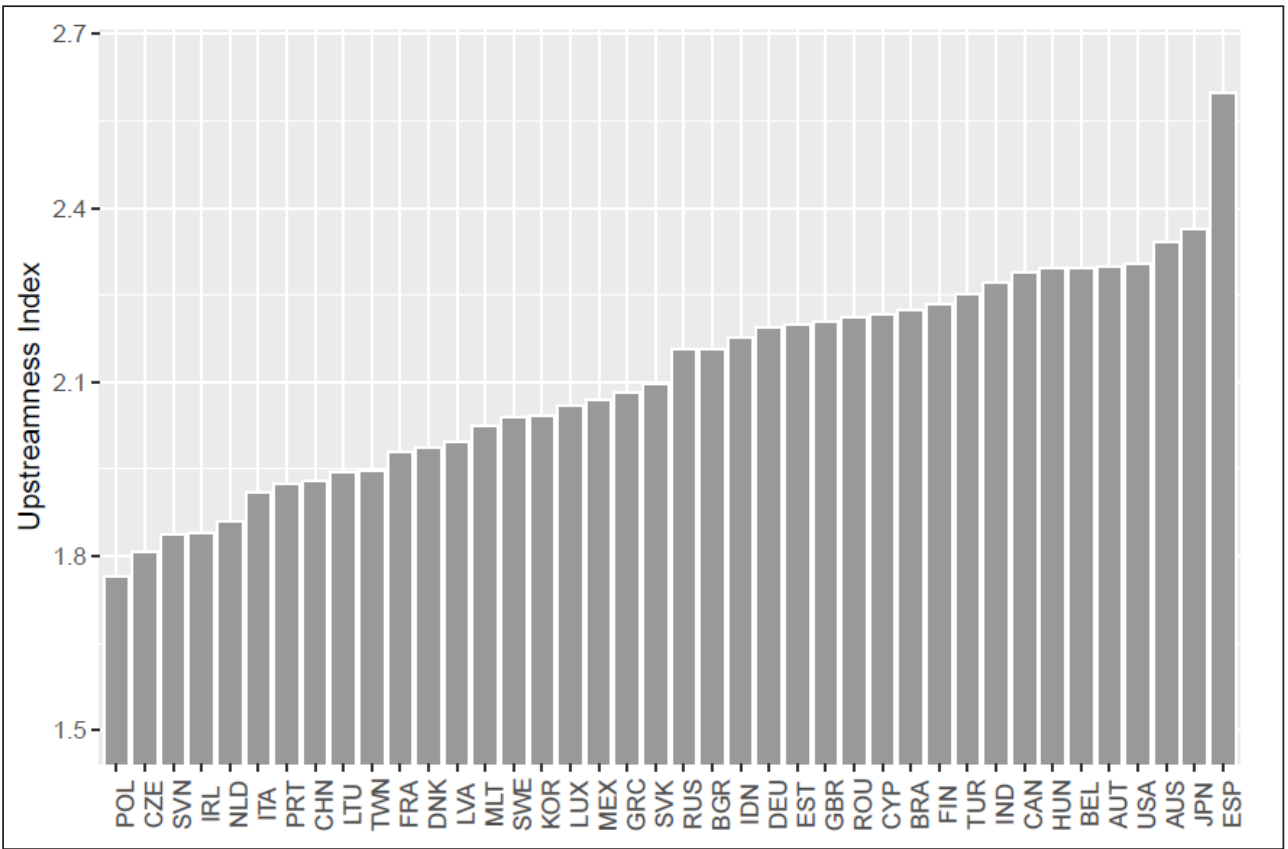

Figure 4. Average upstreamness by country

\section{A Regression Model of Markup}

What attributes are common to the sectors in the high-markup range? Table 2 shows the results from an OLS regression model having markup, measured as the ratio between price and marginal cost, as its dependent variable. The regression model has the number of observations $\mathrm{N}=18799, \mathrm{R}^{2}=0.81$, all variables in $\operatorname{logs}$ and standardized, and heteroskedasticity-corrected standard errors. Some of the variables in the dataset have not been included in the regression model to reduce multicollinearity; these have been identified by their high variance-inflation factor.

Table 2. Regression results, with markup as the dependent variable

\begin{tabular}{llcccc}
\hline Code & Var. Name & Estimate & Std. Error & p. Value \\
\cline { 4 - 5 } CAP & Capital Compensation (mil) & 0.015 & 0.003 & 0.000 \\
COMP & Compensation of Employees (mil) & 0.014 & 0.006 & 0.012 \\
EMP & No. of Persons Engaged (1,000) & -0.054 & 0.006 & 0.000 \\
GFCF_P & Price Level GFCF & -0.014 & 0.009 & 0.100 \\
GO_P & Price Level Gross Output & 0.018 & 0.009 & 0.041
\end{tabular}




\begin{tabular}{|c|c|c|c|c|}
\hline GO_QI & Gross Output, Volume Indices & 0.121 & 0.010 & 0.000 \\
\hline H_HS & $\begin{array}{l}\text { Hours Worked by High-Skilled } \\
\text { Persons (share) }\end{array}$ & -0.058 & 0.013 & 0.000 \\
\hline H_MS & $\begin{array}{l}\text { Hours Worked by Medium-Skilled } \\
\text { Persons (share) }\end{array}$ & -0.172 & 0.016 & 0.000 \\
\hline II_QI & $\begin{array}{l}\text { Intermediate Inputs, Volume } \\
\text { Indices }\end{array}$ & -0.097 & 0.009 & 0.000 \\
\hline LABHS & $\begin{array}{l}\text { High-Skilled Labour } \\
\text { Compensation (share) }\end{array}$ & 0.114 & 0.013 & 0.000 \\
\hline LABMS & $\begin{array}{l}\text { Medium-Skilled Labour } \\
\text { Compensation (share) }\end{array}$ & 0.154 & 0.016 & 0.000 \\
\hline VA_QI & $\begin{array}{l}\text { Gross Value Added, Volume } \\
\text { Indices }\end{array}$ & -0.019 & 0.004 & 0.000 \\
\hline theta & Intermediate-Input Elasticity & 0.717 & 0.005 & 0.000 \\
\hline alpha & $\begin{array}{l}\text { Intermediate-Input Share in } \\
\text { Output }\end{array}$ & -1.208 & 0.005 & 0.000 \\
\hline upstrIndex & $\begin{array}{l}\text { Upstreamness (Upstream Sectors } \\
=\text { Higher Index) }\end{array}$ & 0.026 & 0.003 & 0.000 \\
\hline
\end{tabular}

According to these results, a high-markup sector would be one that has high compensation to capital and employees of all categories, a high price level for output, low number of persons engaged, and a high volume of output. These results suggest that sectors relying more on capital than labour tend to practice higher markups. This idea is consistent with the effects of the calculated variables $\theta$ and $\alpha$ : the intermediate input elasticity variable, $\theta$, has a positive effect of on markup. In other words, sectors having output more elastic with respect to the intermediate input are more likely to be in the high-markup category. (Note that labour qualifies as intermediate input in the production-approach model.) The same is true for sectors with low intermediate-input value share in output, $\alpha$.

Our variable of interest, the upstreamness index, shows a positive effect on markup, indicating that sectors providing raw materials and primary intermediate inputs tend to enjoy higher market power. A possible reason could be that raw material sectors such as oil and gas are capital-intensive and enjoy long-term leases and government licences for the exploitation of natural resources.

Finding a positive effect of upstreamness on markup is important because it supports the idea that any final product, even one traded in an otherwise competitive market, can incorporate a significant markup in its price via intermediate input prices. In other words, this result contributes to a better understanding of the double marginalization problem in the vertical (or successive) monopoly model of market structure. 


\section{Conclusions}

A method proposed in Robert E. Hall, Blanchard, and Hubbard (1986) and Robert E. Hall (1988) to calculate price to marginal cost ratios (markups) based on production data and applied to the publicly available World Input-Output Database (WIOD) allows calculating the distribution of markups across sectors and countries, some common features among high-markup sectors, and the effect of an upstreamness index on markups. Among the sectoral characteristics found to enhance market power are high levels of capital compensation, price levels of gross output, and a low share of intermediate-input value in output. This research also consolidates previous results concerning the levels of the price to marginal cost ratio at the industry level of aggregation.

A novel finding of this research is a positive effect of the upstreamness index on markup, showing that raw material or other intermediate product sectors tend to enjoy a greater market power than downstream sectors. To my knowledge, this is the first empirical study of double (or multiple) marginalization using global industry-level data. This finding is important in two ways. First, it validates successive monopoly models of market structure in the vein of Spengler (1950) and Machlup and Taber (1960). Second, it shows that virtually all final products incorporate substantial price markups via the intermediate goods used in their production.

A possible direction for further research might seek to identify commonalities among countries with similar levels of market power. Another useful direction could try to use a multilevel regression model for markup instead of OLS to consider country heterogeneity.

\section{Acknowledgements}

I thank two anonymous referees for excellent feedback. The following $R$ packages have been used in this research: base R (R Core Team, 2019), papaja (Aust and Barth, 2018), readxl (Wickham and Bryan, 2019), tidyverse (Wickham, 2017), knitr (Xie, 2015), kableExtra (Zhu, 2019), wiod (Quast and Reiter, 2019), prodest (Rovigatti, 2017b), ioanalysis (Wade and Sarmiento-Barbieri, 2019), and ggplot2 (Wickham, 2016). 


\section{References}

Ackerberg, Daniel A.; Caves, Kevin; Frazer, Garth. (2015). Identification properties of recent production function estimators. Econometrica 83(6): 2411-2451. https://doi.org/https://doi.org/10.3982/ECTA13408.

Antràs, Pol; Chir, Davin; Fally, Thibault; Hillberry, Russell. (2012a). Measuring the upstreamness of production and trade flows. Working Paper 17819. Working Paper Series. National Bureau of Economic Research. https://doi.org/10.3386/ w17819.

(2012b). Measuring the upstreamness of production and trade flows. American Economic Review 102(3): 412-416. https://doi.org/10.1257/aer.102.3.412.

Aust, Frederik; Barth, Marius. (2018). papaja: Create APA manuscripts with $R$ markdown. https://github.com/crsh/papaja.

Bresnahan, Timothy F.; Reiss, Peter C. (1985). Dealer and manufacturer margins. The RAND Journal of Economics 16(2): 3-268.

De Loecker, Jan. (2011). Recovering markups from production data. International Journal of Industrial Organization 29(3): 350-355.

De Loecker, Jan; Eeckhout, Jan. (2017). The rise of market power and the macroeconomic implications. Working Paper 23687. Working Paper Series. National Bureau of Economic Research. https://doi.org/10.3386/w23687.

(2018). Global market power. National Bureau of Economic Research.

De Loecker, Jan; Eeckhout, Jan; Unger, Gabriel. (2020). The Rise of Market Power and the Macroeconomic Implications. The Quarterly Journal of Economics 135(2): 561-644. https://doi.org/10.1093/qje/qjz041.

De Loecker, Jan; Goldberg, Pinelopi K.; Khandelwal, Amit K.; Pavcnik, Nina. (2016). Prices, markups, and trade reform. Econometrica 84(2): 445-510. https://doi. org/10.3982/ECTA11042.

De Loecker, Jan; Warzynski, Frederic. (2012). Markups and firm-level export status. The American Economic Review 102(6): 2437-2471. http://www.jstor. org/stable/41724661.

Ennis, Sean F.; Gonzaga, Pedro; Pike, Chris. (2019). Inequality: A hidden cost of market power. Oxford Review of Economic Policy 35(3): 518-549. https://doi. org/10.1093/oxrep/grz017.

Erumban, Abdul Azeez; Gouma, Reitze; de Vries, Gaaitzen; de Vries, Klaas; Timmer, Marcel. (2012). WIOD socio-economic accounts (SEA): Sources and methods. http://www.wiod.org/publications/source_docs/SEA_Sources.pdf.

Hall, Robert E. 1988. The relation between price and marginal cost in U.S. industry. Journal of Political Economy 96(5): 921-947. https://doi.org/10.1086/261570. (2018). New evidence on the markup of prices over marginal costs and the role of mega-firms in the US economy. Working Paper 24574. Working Paper Series. National Bureau of Economic Research. https://doi.org/10.3386/w24574. 
Hall, Robert E.; Blanchard, Olivier Jean; Hubbard, R. Glenn. (1986). Market structure and macroeconomic fluctuations. Brookings Papers on Economic Activity 1986(2): 285-338.

Han, Minsoo; Pyun, Ju Hyun. 2020. Markups and income inequality: Causal links, 1975-2011. Journal of Comparative Economics. https://doi.org/https://doi. org/10.1016/j.jce.2020.12.002.

Joolman. 2020. Getting started ioanalysis v 0.3.3. https://github.com/joolman/ ioanalysis/blob/master/Getting.

Levinsohn, James; Petrin, Amil. (2003). Estimating production functions using inputs to control for unobservables. Review of Economic Studies 70(2): 317-341. https://EconPapers.repec.org/RePEc:oup:restud:v:70:y:2003:i:2:p:317-341.

Machlup, Fritz; Taber, Martha. (1960). Bilateral monopoly, successive monopoly, and vertical integration. EConomica 27(106): 101-119. http://www.jstor.org/ stable/2550895.

Montero, José Manuel; Urtasun, Alberto. (2021). Markup dynamics and financial frictions: The Spanish case. International Review of Economics \& Finance 71: 316-341. https://doi.org/https://doi.org/10.1016/j.iref.2020.08.006.

Olley, G. Steven; Pakes, Ariel. (1996). The dynamics of productivity in the telecommunications equipment industry. Econometrica 64(6): 1263-1297. http:// www.jstor.org/stable/2171831.

Quast, Bastiaan; Reiter, Oliver. (2019). WIOD: World Input Output Database Release 2013 and Release 2016.

$\mathrm{R}$ Core Team. (2019). R: A language and environment for statistical computing. Vienna, Austria: R Foundation for Statistical Computing. https://www.R-project. org/.

Rovigatti, Gabriele. (2017a). Production function estimation in r: The Prodest Package. Journal of Open Source Software 2(18): 371. https://doi.org/10.21105/ joss.00371.

(2017b). Production function estimation in r: The Prodest Package. Working Paper.

Spengler, Joseph J. (1950). Vertical integration and antitrust policy. Journal of Political Economy 58(4): 347-352.

Thomas, Lacy Glenn. (1980). Monopoly and the distribution of wealth: A reappraisal. The Quarterly Journal of Economics 94(1): 185-194. http://www.jstor.org/ stable/1884612.

Timmer, Marcel P.; Dietzenbacher, Erik; Los, Bart; Stehrer, Robert; de Vries, Gaaitzen J. (2015). An illustrated user guide to the World Input-Output Database: The case of global automotive production. Review of International Economics 23(3): 575-605. https://doi.org/https://doi.org/10.1111/roie.12178.

Wade, John; Sarmiento-Barbieri, Ignacio. (2019). Ioanalysis: Input output analysis. https://CRAN.R-project.org/package=ioanalysis. 
Wickham, Hadley. (2016). Ggplot2: Elegant graphics for data analysis. New York: Springer-Verlag. https://ggplot2.tidyverse.org.

(2017). Tidyverse: Easily install and load the 'Tidyverse'. https://CRAN.R-project. org/package=tidyverse.

Wickham, Hadley; Bryan, Jennifer. (2019). Readxl: Read Excel files. https:// CRAN.R-project.org/package=readxl.

WIOD-SEA. (2018). World Input-Output Database. WIOD Home. http://www. wiod.org/home.

World IO Tables. (2018). World Input-Output Database. http://www.wiod.org/ database/wiots16.

Xie, Yihui. (2015). Dynamic documents with $R$ and Knitr. $2^{\text {nd }}$ ed. Boca Raton, Florida: Chapman; Hall/CRC. https://yihui.name/knitr/.

Zhu, Hao. 2019. kableExtra: Construct complex table with 'kable' and pipe syntax. https://CRAN.R-project.org/package=kableExtra. 